\title{
Effects of grazing intensity on seed production of Caragana stenophylla along a climatic aridity gradient in the Inner Mongolia Steppe, China
}

\author{
XIE Lina ${ }^{1,2}$, CHEN Weizhong ${ }^{2}$, Christopher A GABLER ${ }^{3}$, HAN Lei $^{2}$, GUO Hongyu ${ }^{2}$, CHEN \\ Qing $^{2}$, MA Chengcang ${ }^{2 *}$, GU Song ${ }^{1 *}$ \\ ${ }^{1}$ College of Life Sciences, Nankai University, Tianjin 300071, China; \\ ${ }^{2}$ Tianjin Key Laboratory of Animal and Plant Resistance, College of Life Sciences, Tianjin Normal University, Tianjin 300387, \\ China; \\ ${ }^{3}$ Department of Biology and Biochemistry, University of Houston, Houston 77204, USA
}

\begin{abstract}
As the increases of climatic aridity and grazing intensity, shrubs play an increasingly important role in grassland ecosystem in arid and semi-arid regions, and its abundance also generally increases. However, the effects of climatic aridity and grazing intensity on sexual reproduction of shrubs in grassland remain largely unclear. In order to understand the effects of grazing intensity and climatic drought stress, and their interaction on seed production of shrub species, we examined the seed number, seed weight and seed yield of Caragana stenophylla under three grazing intensities (fenced, mild grazing and severe grazing) across a climatic aridity gradient (semi-arid, arid, very arid and intensively arid zones) in the Inner Mongolia Steppe, northern China during 2012-2013. The seed number, seed weight and seed yield gradually increased from the semi-arid to the very arid zones, but decreased from the very arid to the intensively arid zones in fenced plots. The seed number and seed yield decreased from the semi-arid to the intensively arid zones in mild and severe grazing treatment plots, therefore, grazing enhanced the suppression effect of climatic aridity on seed production of $C$. stenophylla. The seed number and seed yield gradually decreased as grazing intensity increased. The seed weight was highest in severe grazing plots, followed by the mild grazing plots and then the fenced plots. Precipitation varied interannually during the study period. We observed that the seed number, seed weight and seed yield were lower in the low precipitation year (2013) than in the high precipitation year (2012). As climatic drought stress increased, the negative effects of grazing on seed production of $C$. stenophylla also gradually increased. Our results indicated that climatic drought stress may contribute to the encroachment of $C$. stenophylla shrub in arid zones by promoting its seed production. However, grazing had negative effects on sexual reproduction of $C$. stenophylla, and the combined effects of drought stress and grazing seriously suppressed sexual reproduction of $C$. stenophylla in the intensively arid zone.
\end{abstract}

Keywords: grazing; seed number; seed weight; seed yield; arid and semi-arid zones; Caragana stenophylla

Citation: XIE Lina, CHEN Weizhong, Christopher A GABLER, HAN Lei, GUO Hongyu, CHEN Qing, MA Chengcang, GU Song. 2016. Effects of grazing intensity on seed production of Caragana stenophylla along a climatic aridity gradient in the Inner Mongolia Steppe, China. Journal of Arid Land, 8(6): 890-898. doi: 10.1007/s40333-016-0050-7

It is well known that aridity influences plant reproductive behavior, but few studies have examined the changes in seed production along a climatic aridity gradient. Previous studies have

\footnotetext{
*Corresponding author: MA Chengcang (E-mail: machengcang@163.com); GU Song (E-mail: songgu@nankai.edu.cn) Received 2015-12-02; revised 2016-01-27; accepted 2016-04-14

(C) Xinjiang Institute of Ecology and Geography, Chinese Academy of Sciences, Science Press and Springer-Verlag Berlin Heidelberg 2016
} 
shown that, as the degree of climatic aridity increased, the reproductive biomass (Volis et al., 2002), seed yield (May et al., 2013), seed mass (Romo-Campos et al., 2010; Harel et al., 2011; May et al., 2013) and seed vigor (Volis et al., 2004) of herbaceous plants in grasslands decreased. For example, the number, height and biomass of reproductive shoots and the number of seeds per inflorescence of Leymus chinensis all decreased as the aridity increased in Northeast China (Wang et al., 2003; Wang and Gao, 2003, 2004); and the seed biomass and seed vigor of Hordeum spontaneum and Avena sterilis decreased as the aridity increased in Israel (Volis et al., 2002, 2004; Volis, 2007). However, some previous studies also showed that seed production of plant community was significantly greater in a semi-arid environment than in a comparable Mediterranean environment (Lebrija-Trejos et al., 2011). Moreover, some other studies found that there were no clear trends in seed or pod-related traits along the aridity gradients, e.g. in Medicago polymorpha from arid to humid zones (Del Pozo et al., 2002). However, the study on the variation in seed production of shrub species along a climatic aridity gradient has not been found.

Grazing can influence seed production in various grassland plant species, and often does so in somewhat complex ways. Some previous studies have shown that a variety of seed production metrics (e.g. reproductive shoot number, flower number, fruit number, seed mass and reproductive biomass) decreased as increasing grazing intensity for many plant species, specifically for Atriplex vesicaria (Hunt, 2001), Ruellia humilis and Amorpha canescens (Hickman and Hartnett, 2002), Carex bigelowii (Bråthen and Junttila, 2006), Stipa grandis, Agropyron cristatum and Cleistogenes squarrosa (Wan et al., 2011). In contrast, Liu et al. (2010) pointed out that grazing increased the seed production of unpalatable plants species, such as Ligularia narynensis. Therefore, more studies are needed to better understand the general effects of grazing on seed production and its mechanisms in different grassland ecosystems.

The climate in the Inner Mongolia Steppe is characterized by a gradual increase in solar radiation and air temperature while a decrease in precipitation from the northeast to the southwest. Among these environmental factors, precipitation plays a crucial role in plant growth and development. Decreased precipitation paired with increased evaporation (due to increases in solar radiation and air temperature) result in an increasing of climatic aridity from the northeast to the southwest. Seven moisture zones are defined in this region with the orders of humid, sub-humid, semi-arid, arid, very arid, intensively arid and extremely arid zones from the northeast to the southwest (Yang et al., 1987). With its strong climatic aridity gradient, the Inner Mongolia Steppe provides an ideal system for us to explore the effects of climatic aridity gradient on seed production of shrubs. Grazing is one of the important disturbances in the Inner Mongolia Steppe. The domestic animals in the steppe are mainly goat and sheep. Overgrazing has become a common phenomenon since the 1970 s, and it is a main cause of grassland degradation in the Inner Mongolia Steppe (Chen and Wang, 2000; Li et al., 2000).

Thicketization or proliferation of shrubs in grasslands, has become common in the Inner Mongolia Steppe, and Caragana species are the major encroaching shrubs (Xiong et al., 2003). There are 16 Caragana species distributed in the Inner Mongolia Steppe. Among which, Caragana stenophylla is one of the key species with important ecological functions in the region. C. stenophylla, a deciduous and spinose shrub species with relative compact cushion-like canopies, is distributed across a large geographic range in the Inner Mongolia Steppe, predominately from the semi-arid zone to the intensively arid zone (Ma et al., 2013; Xie et al., 2015).

In this study, we hypothesized that, like most grassland plants, climatic aridity and grazing would decrease the seed production of $C$. stenophylla, and that greater climatic aridity could strengthen the negative effects of grazing on seed production. To test our hypotheses, we examined the seed number, seed weight and seed yield of $C$. stenophylla under three grazing intensities (fenced, mild grazing and severe grazing) across a climatic aridity gradient in the Inner Mongolia Steppe where C. stenophylla is present (semi-arid, arid, very arid and intensively arid zones). 


\section{Study area and methods}

\subsection{Study area}

We conducted field investigations in four sites, i.e. Xilinhot city in the semi-arid zone, Siziwang Banner in the arid zone, Etog Banner in the very arid zone and Alxa Left Banner in the intensively arid zone of the Inner Mongolia Steppe in northern China. Environmental data for the study sites are summarized in Table 1. The field surveys and experiments were conducted in 2012 and 2013. Precipitation was relatively high in 2012 and relatively low in 2013.

Table 1 Location and environmental data of the four field sites in the Inner Mongolia Steppe

\begin{tabular}{|c|c|c|c|c|c|c|c|c|c|}
\hline Site & $\begin{array}{c}\text { Longitude } \\
\left({ }^{\circ} \mathrm{E}\right)\end{array}$ & $\begin{array}{l}\text { Latitude } \\
\left({ }^{\circ} \mathrm{N}\right)\end{array}$ & $\begin{array}{l}\text { Altitude } \\
(\mathrm{m})\end{array}$ & $\begin{array}{l}\text { MAP } \\
(\mathrm{mm})\end{array}$ & $\begin{array}{l}\text { AMT } \\
\left({ }^{\circ} \mathrm{C}\right)\end{array}$ & $\begin{array}{l}\text { SSD } \\
(\mathrm{h} / \mathrm{a})\end{array}$ & $\begin{array}{c}\mathrm{AI} \\
\left(I_{\mathrm{dm}}\right)\end{array}$ & $\begin{array}{l}\text { Climatic } \\
\text { aridity }\end{array}$ & Vegetation type \\
\hline Xilinhot city & $115^{\circ} 55^{\prime} 19^{\prime \prime}$ & $44^{\circ} 28^{\prime} 31^{\prime \prime}$ & 990 & 281 & 2.35 & 2,932 & 22.75 & Semi-arid & Steppe \\
\hline $\begin{array}{l}\text { Siziwang } \\
\text { Banner }\end{array}$ & $111^{\circ} 53^{\prime} 22^{\prime \prime}$ & $41^{\circ} 47^{\prime} 28^{\prime \prime}$ & 1,492 & 240 & 3.40 & 3,065 & 17.91 & Arid & $\begin{array}{c}\text { Desertification } \\
\text { steppe }\end{array}$ \\
\hline Etog Banner & $107^{\circ} 58^{\prime} 02^{\prime \prime}$ & $39^{\circ} 07^{\prime} 02^{\prime \prime}$ & 1,500 & 210 & 6.40 & 3,050 & 12.80 & Very arid & Steppe desert \\
\hline $\begin{array}{c}\text { Alxa Left } \\
\text { Banner }\end{array}$ & $105^{\circ} 41^{\prime} 34^{\prime \prime}$ & $38^{\circ} 19^{\prime} 47^{\prime \prime}$ & 1,561 & 110 & 7.80 & 3,200 & 6.18 & $\begin{array}{c}\text { Intensively } \\
\text { arid }\end{array}$ & Desert \\
\hline
\end{tabular}

Note: Aridity index (AI; $I_{\mathrm{dm}}$ ) was calculated using the de Martonne method (Meng et al., 2004). MAP, mean annual precipitation; AMT, annual mean temperature; SSD, sunshine duration.

\subsection{Field surveys}

Within each study site, we established 3 plots, i.e. a fenced plot, a mild grazing plot (Xilinhot city: 1.2 sheep $/ \mathrm{hm}^{2}$; Siziwang Banner: 1.0 sheep $/ \mathrm{hm}^{2}$; Etog Bauner: 0.8 sheep $/ \mathrm{hm}^{2}$; Alxa Left Banner: $0.4 \mathrm{sheep} / \mathrm{hm}^{2}$ ) and a severe grazing plot (Xilinhot city: $2.8 \mathrm{sheep} / \mathrm{hm}^{2}$; Siziwang Banner: 1.9 sheep $/ \mathrm{hm}^{2}$; Etog Banner: $1.5 \mathrm{sheep} / \mathrm{hm}^{2}$; Alxa Left Banner: 0.8 sheep $/ \mathrm{hm}^{2}$ ). Since vegetation cover decreases gradually with the increase in climatic drought stress from the semi-arid zone to the intensively arid zone, the grazing intensity in each site was set according to local vegetation conditions for logistical reasons, and the intensity of severe grazing was always about twice as high as the intensity of mild grazing in each study site. We divided each plot into 4 sub-plots, and the area of each sub-plot ranged from 1 to $3 \mathrm{hm}^{2}$.

In each sub-plot, we selected five $C$. stenophylla shrub clusters (in total 20 shrub clusters per plot) using the line transect method during the pod ripening season. For each C. stenophylla shrub cluster, we marked a sample branch, which served as the representative for those branches arising via sexual reproduction within the whole shrub cluster. We picked mature pods from the sample branch every day, counted seed number and weighed seed yield (air dried for $7 \mathrm{~d}$ ). After all pod measurement, we cut off the sample branch to measure dry biomass (dried at $80^{\circ} \mathrm{C}$ for $72 \mathrm{~h}$ ).

In each sub-plot, we measured hundred-seed weight (air dried for $7 \mathrm{~d}$ ) by randomly sampling seeds from at least 20 shrub clusters and calculated seed weight, and we did these 3 times per plot in 2012 and 4 times per plot in 2013. In order to eliminate the effect of branch size on seed production, we standardized seed number and seed yield by dividing each by the biomass $(\mathrm{g})$ of the sample branch on which they were counted.

\subsection{Data analysis}

We performed ANOVAs to analyze the differences in means of seed number, seed weight and seed yield among different climatic aridity zones, grazing intensities and experimental years, and to evaluate the interactive effects of climate gradient and grazing intensity on these seed production indices. We used Tukey HSD post-hoc tests to identify the differences among individual treatments. We performed $t$-tests to compare seed number, seed weight and seed yield between the two experimental years. All analyses were performed using SPSS 16.0 (SPSS Inc., USA).

\section{Results}

\subsection{Seed number}

Climatic aridity zones had significant effects on seed number of $C$. stenophylla $\left(F_{3,452}=126.25\right.$, 
$P<0.01$; Fig. 1). In fenced plots, the seed number in both 2012 and 2013 tended to increase from the semi-arid zone to the very arid zone, but there was a significant decrease in seed number in the intensively arid zone. Under both mild grazing and severe grazing, the seed number gradually decreased from the semi-arid zone to the intensively arid zone.

There was a significant decrease in the seed number as grazing intensity increased $\left(F_{2,452}=432.80\right.$, $P<0.01$; Fig. 1) in both 2012 and 2013. We observed very few or no pods in severe grazing plots. The seed number was lower in 2013 (low precipitation year) than in 2012 (high precipitation year) $\left(F_{1,452}=31.87, P<0.01\right.$; Fig. 1$)$.

The interaction between climatic aridity and grazing intensity had highly significant effects on seed number of $C$. stenophylla $\left(F_{6,452}=47.11, P<0.01\right)$. As climatic drought stress increased, the negative effects of grazing on seed number of $C$. stenophylla gradually increased. Compared to the fenced plots, the seed number in mild grazing plots decreased by $42.5 \%$ in the semi-arid zone, $69.8 \%$ in the arid zone, $82.0 \%$ in the very arid zone and $79.8 \%$ in the intensively arid zone; while in severe grazing plots it decreased by $88.7 \%$ in the semi-arid zone, $89.9 \%$ in the arid zone, $94.3 \%$ in the very arid zone and $100.0 \%$ in the intensively arid zone.
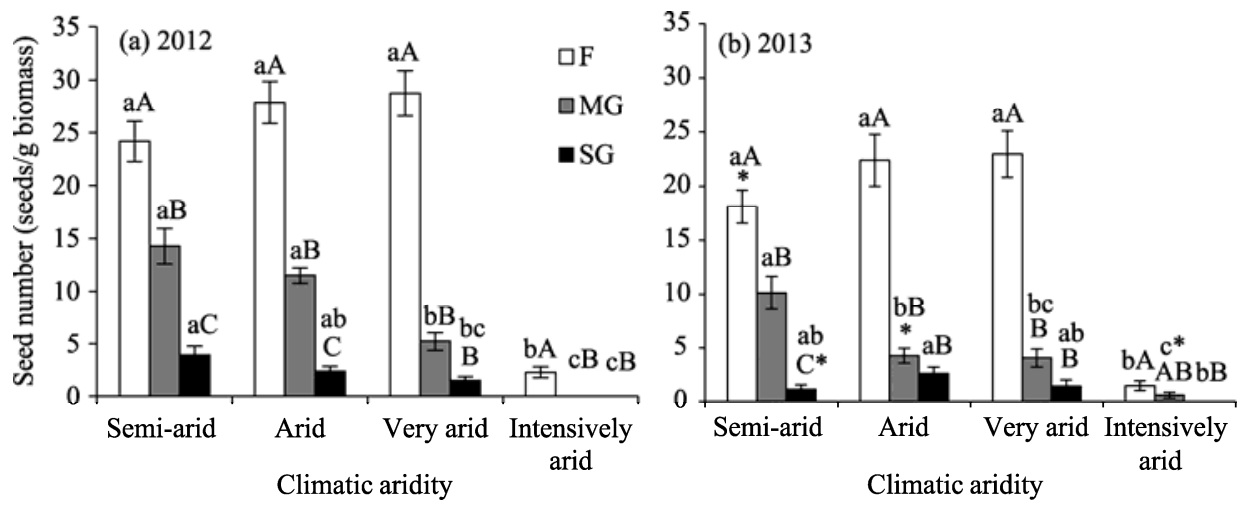

Fig. 1 Effects of climatic aridity and grazing intensity on seed number of C. stenophylla in 2012 (a) and 2013 (b). Error bars indicate standard error. $n=20$. F, fenced; MG, mild grazing; SG, severe grazing. For the same grazing intensity in each year, different lowercase letters indicate significant differences between climatic aridity; for the same climatic aridity in each year, different uppercase letters indicate significant differences between grazing intensities (Tukey HSD tests, $P<0.05$ ); and for a particular climatic aridity zone and grazing intensity, the asterisks indicate significant differences between 2012 and 2013 ( $t$-tests, $P<0.05$ ).

\subsection{Seed weight}

In 2012, the seed weight of $C$. stenophylla gradually increased from the semi-arid zone to the very arid zone, but decreased from the very arid zone to the intensively arid zone $\left(F_{3,55}=23.02, P<0.01\right.$; Fig. 2). However, in 2013, the seed weight of C. stenophylla did not show significant changes along the climatic aridity gradients.

Grazing had significant effects on seed weight of $C$. stenophylla $\left(F_{2,55}=40.73, P<0.01\right.$; Fig. 2$)$. The seed weight of $C$. stenophylla was highest in severe grazing plots. Moreover, the seed weight in mild grazing plots was slightly lower than that in fenced plots, but the difference was not statistical significant in most climatic aridity zones except for the intensively arid zone in 2013.

The seed weight of $C$. stenophylla was lower in 2013 than in $2012\left(F_{1,55}=451.46, P<0.01\right.$; Fig. $2)$. There was no significant interaction effect between climatic aridity zone and grazing intensity on seed weight of $C$. stenophylla.

\subsection{Seed yield}

Climatic aridity had significant effects on seed yield of $C$. stenophylla $\left(F_{3,452}=124.38, P<0.01\right.$; Fig. 3 ). In fenced plots, the seed yield gradually increased from the semi-arid zone to the very arid zone, but decreased significantly in the intensively arid zone. Under both mild grazing and severe grazing, the seed yield gradually decreased from the semi-arid zone to the intensively arid zone.

There was a significant decrease in the seed yield as grazing intensity increased $\left(F_{2,452}=440.18\right.$, 
$P<0.01$; Fig. 3). In 2012 , the seed yield in the very arid zone were $414.0 \pm 30.7 \mathrm{mg} / \mathrm{g}$ biomass in fenced plots, $73.0 \pm 11.8 \mathrm{mg} / \mathrm{g}$ biomass in mild grazing plots and $24.2 \pm 5.6 \mathrm{mg} / \mathrm{g}$ biomass in severe grazing plots.

The seed yield in 2013 was about $30 \%-50 \%$ lower than that in $2012\left(F_{1,452}=91.71, P<0.01\right.$; Fig. $3)$. There was a highly significant interaction between climatic aridity and grazing intensity on seed yield of $C$. stenophylla $\left(F_{6,452}=51.39, P<0.01\right)$, indicating that the negative effects of grazing on seed yield gradually increased as climatic drought stress increased. The negative effects of mild grazing on seed yield occupied $43.3 \%$ of the total yield in the semi-arid zone, $71.8 \%$ in the arid zone, $83.4 \%$ in the very arid zone and $82.4 \%$ in the intensively arid zone. Moreover, the negative effects of severe grazing on seed yield accounted $87.6 \%$ of the total yield in the semi-arid zone, $89.2 \%$ in the arid zone, $93.5 \%$ in the very arid zone and $100.0 \%$ in the intensively arid zone.


Fig. 2 Effects of climatic aridity and grazing on seed weight of C. stenophylla in 2012 (a) and 2013 (b). Error bars indicate standard error. $n=20$. We used $t$-tests to compare seed weights between fenced and mild grazing plots in the intensively arid zone because no mature seeds were observed in the severe grazing plots.
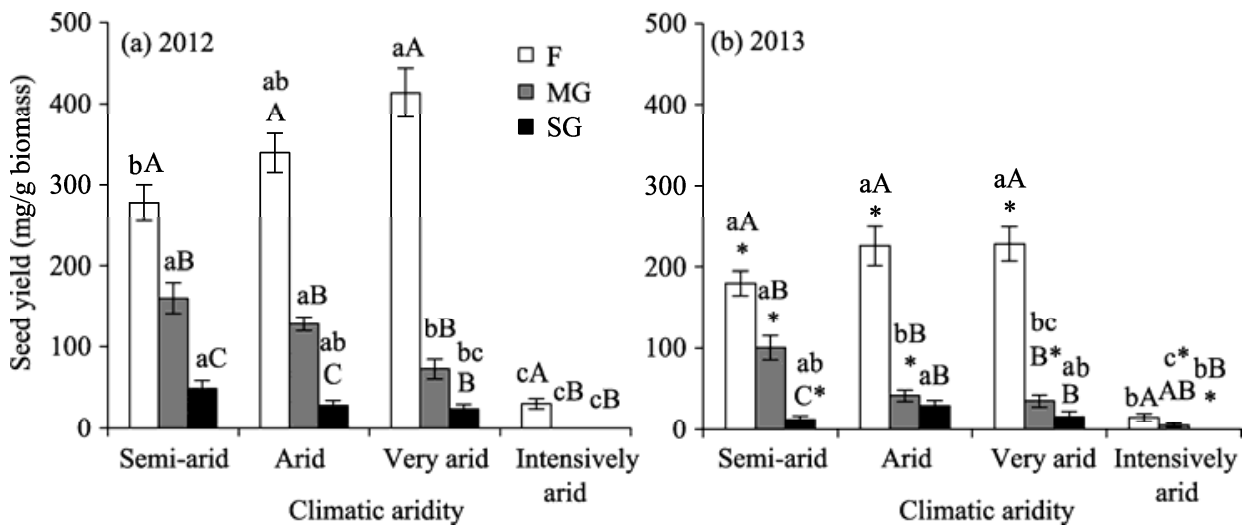

Fig. 3 Effects of climatic aridity and grazing intensity on seed yield of C. stenophylla in 2012 (a) and 2013 (b). Error bars indicate standard error. $n=20$.

\section{Discussion}

\subsection{Effect of climatic drought stress on seed production of $C$. stenophylla}

Without grazing pressure, the seed number, seed weight and seed yield of C. stenophylla gradually increased from the semi-arid zone to the very arid zone, but significantly decreased from the very arid zone to the intensively arid zone. As a result, the seed production of $C$. stenophylla was highest in the very arid zone. Our result is in contrast to other studies that the seed production of herbaceous plants decreased as drought stress increased (Wang et al., 2003; 
Wang and Gao, 2003, 2004; Harel et al., 2011). It is likely that C. stenophylla becomes more dominant from the semi-arid zone to the very arid zone because this shrub species is highly adapted to the arid climate (Ma et al., 2004a, b, 2008, 2014; Zhang et al., 2011) while many of its herbaceous competitors are comparatively sensitive to drought stress. The benefits of reduced interspecific competition might compensate for the negative effects of increased drought stress, high temperature and intense solar radiation. C. stenophylla had taller canopies and greater canopy areas in the very arid zone than in the arid and semi-arid zones (Ma et al., 2013), and greater canopy size could lead to more and larger seeds, increasing seed yield. An increase in seed production as climatic drought stress increases is considered one of the key characteristics in the adaptation of $C$. stenophylla to arid environments, as well as one of the key traits promoting its gradual increase in dominance from the semi-arid zone to the very arid zone (Zhang et al., 2002; Ma et al., 2004a).

Without grazing pressure, the seed number, seed weight and seed yield of C. stenophylla decreased from the very arid zone to the intensively arid zone. This indicates an upper limit to the drought stress tolerance of $C$. stenophylla, beyond which its seed production is strongly hindered. The most likely mechanism of this decrease is that the intense drought, high temperature and intense solar radiation stresses reduce the nutrient assimilation (Zhou et al., 2005), which leads to increases in aborted flowers and dropped fruits (Fang et al., 2010), and thus hinders the seed development. These results suggest that, although $C$. stenophylla has acquired many adapted characteristics to cope with harsh environments (Ma et al., 2004a, b, 2008, 2014; Zhang et al., 2011; Xie et al., 2014), these characteristics may be insufficient for adapting the intensively climatic arid environments.

\subsection{Effect of grazing intensity on seed production of C. stenophylla}

Previous studies have shown that many plant species produce fewer fruits under grazed conditions compared to ungrazed conditions, including Trientalis europaea (Piqueras, 1999), Echinopsis terscheckii (Peco et al., 2011), Carnegiea gigantean (Hayes et al., 2013) and members of the family Polemoniaceae (Becklin and Kirkpatrick, 2006). However, some studies showed that grazing do not affect the fruit number of Anemone coronaria (Perevolotsky et al., 2011), and it can increase the seed production of Ligularia narynensis (Liu et al., 2010). In the four climatic aridity zones that $C$. stenophylla distributed in the Inner Mongolia Steppe, the seed number and seed yield of $C$. stenophylla significantly decreased as grazing intensity increased. This pattern might be due to the direct consumption of flowers and fruits by livestock.

Previous studies also have shown that grazing decreased the seed weights of Leymus chinensis (Wang et al., 2011), maize (Silva et al., 2012) and various native plant species in the Monte Desert of Argentina (Cerda et al., 2012). In our study, the seed weight in severe grazing plots was significantly higher than those in mild grazing and fenced plots. It is likely because the increased grazing intensity significantly decreased the fruit abundance. In severe grazing plots, only the fruits hidden in shrub canopies survived from the grazing, resulting in C. stenophylla individuals only produced very few mature fruits. Specifically, the seed abundance in severe grazing plots was $0-16.3 \%$ of that in fenced plots. Thus, we presume that a much greater share of resources is allocated to the individual seed when fruits themselves are scarce.

\subsection{Interactive effects between climatic drought stress and grazing intensity on seed production of $C$. stenophylla}

Although the seed yield of $C$. stenophylla increased from the semi-arid zone to the very arid zone under ungrazed conditions, it significantly decreased from the semi-arid zone to the intensively arid zone under grazed conditions. This suggests that the seed production of C. stenophylla gradually decreases as drought stress, temperature and solar radiation increase under grazing conditions, and grazing enhances the suppression effect of climatic aridity on seed production. Historically, grazing is relatively common in the Inner Mongolia Steppe, and the decreased seed yield of C. stenophylla under grazing is likely a major driver of the observed decrease in sexual reproduction of $C$. stenophylla from the semi-arid zone to the intensively arid zone (Ma et al., 
2013). However, there is an associated increase in asexual reproduction via ramets from the semi-arid zone to the intensively arid zone in grazing plots (Ma et al., 2013), which may compensate for the decrease in sexual reproduction of $C$. stenophylla.

As increasing climatic drought stress, the negative effects of grazing on seed production of $C$. stenophylla also increase. In the semi-arid zone, compared with the spinose C. stenophylla species, sheep prefer to feed on grasses, thus grazing has little effect on seed production of $C$. stenophylla. However, as climatic drought stress gradually increases from the semi-arid zone to the intensively arid zone, the percentage of herbaceous plant cover gradually decreases while the plant cover of $C$. stenophylla gradually increases, thus the ratio of shrub cover to grass cover gradually increases. In the intensively arid zone, herbaceous plant cover is very low, and C. stenophylla is the dominant species (Ma et al., 2004a), making C. stenophylla becoming the main forage plant species for livestock. As a result, grazing has the strongest negative effects on seed production of C. stenophylla in the intensively arid zone. These results suggest that grassland ecosystems are increasingly susceptible to grazing disturbance as drought stress, temperature and solar radiation increase from the semi-arid zone to the intensively arid zone. These findings indicate that special efforts should be taken to appropriately manage grazing in the very arid and intensively arid zones.

\section{Conclusions}

In this study, we examined the effects of grazing intensity and climatic drought stress on seed production of C. stenophylla in the Inner Mongolia Steppe, northern China. Without grazing, the seed production of $C$. stenophylla increased from the semi-arid to the very arid zones, but significantly decreased from the very arid to the intensively arid zones. Grazing inhibited the seed production of $C$. stenophylla in the Inner Mongolia Steppe. It enhanced the suppression effect of climatic aridity on seed production of $C$. stenophylla. Moreover, climatic aridity strengthened the negative effects of grazing on seed production of $C$. stenophylla.

These results suggested that in terms of seed production, climatic aridity may contribute to increasing shrub encroachment from the semi-arid zone to the very arid zone in the Inner Mongolia Steppe by promoting the seed production of $C$. stenophylla shrubs. But grazing had negative effects on the abundance of $C$. stenophylla shrubs. The combined effect of climatic drought and grazing seriously suppressed recruitment by sexual reproduction of $C$. stenophylla in the intensively arid zone.

\section{Acknowledgments}

This work was supported by the National Natural Science Foundation of China $(31570453,31170381,31270502$, 31300386), the PhD Candidate Research Innovation Fund of Nankai University and the Doctoral Fund of Tianjin Normal University (52XB1208). We thank Xilinhot City Grassland Work Station, Siziwang Banner Grassland Work Station, Etog Banner Grassland Work Station and Alxa Left Banner Grassland Work Station for the logistical support of this study.

\section{References}

Becklin K M, Kirkpatrick H E. 2006. Compensation through rosette formation: the response of scarlet gilia (Ipomopsis aggregata: Polemoniaceae) to mammalian herbivory. Canadian Journal of Botany, 84(8): 1298-1303.

Bråthen K A, Junttila O. 2006. Infertile times: response to damage in genets of the clonal sedge Carex bigelowii. Plant Ecology, 187(1): 83-95.

Cerda N V, Tadey M, Farji-Brener A G, et al. 2012. Effects of leaf-cutting ant refuse on native plant performance under two levels of grazing intensity in the Monte Desert of Argentina. Applied Vegetation Science, 15(4): 479-487.

Chen Z Z, Wang S P. 2000. Chinese Typical Grassland Ecosystem. Beijing: Science Press, 106-109. (in Chinese)

Del Pozo A, Ovalle C, Aronson J, et al. 2002. Ecotypic differentiation in Medicago polymorpha L. along an environmental gradient in central Chile. I. Phenology, biomass production and reproductive patterns. Plant Ecology, 159(2): 119-130.

Fang X W, Turner N C, Yan G J, et al. 2010. Flower numbers, pod production, pollen viability, and pistil function are reduced 
and flower and pod abortion increased in chickpea (Cicer arietinum L.) under terminal drought. Journal of Experimental Botany, 61(2): 335-345.

Harel D, Holzapfel C, Sternberg M. 2011. Seed mass and dormancy of annual plant populations and communities decreases with aridity and rainfall predictability. Basic and Applied Ecology, 12(8): 674-684.

Hayes C L, Talbot W A, Wolf B O. 2013. Woodrat herbivory influences saguaro (Carnegiea gigantea) reproductive output. Journal of Arid Environments, 89: 110-115.

Hickman K R, Hartnett D C. 2002. Effects of grazing intensity on growth, reproduction, and abundance of three palatable forbs in Kansas tallgrass prairie. Plant Ecology, 159(1): 23-33.

Hunt L P. 2001. Low seed availability may limit recruitment in grazed Atriplex vesicaria and contribute to its local extinction. Plant Ecology, 157(1): 53-67.

Lebrija-Trejos E, Lobato M C C, Sternberg M. 2011. Reproductive traits and seed dynamics at two environmentally contrasting annual plant communities: From fieldwork to theoretical expectations. Israel Journal of Ecology \& Evolution, 57(1-2): 73-90.

Li S G, Harazono Y, Oikawa T, et al. 2000. Grassland desertification by grazing and the resulting micrometeorological changes in Inner Mongolia. Agricultural and Forest Meteorology, 102(2-3): 125-137.

Liu D, An S Z, Kong Q G, et al. 2010. Population characters of Ligularia narynensis in Kalajun rangeland. Pratacultural Science, 27(4): 25-29. (in Chinese)

Ma C C, Gao Y B, Jiang F Q, et al. 2004a. The comparison studies of ecological and water regulation characteristics of Caragana microphylla and Caragana stenophylla. Acta Ecologica Sinica, 24(7): 1442-1451. (in Chinese)

Ma C C, Gao Y B, Wang J L, et al. 2004b. The comparison studies of photosynthetic characteristics and protective enzymes of Caragana microphylla and Caragana stenophylla. Acta Ecologica Sinica, 24(8): 1594-1601. (in Chinese)

Ma C C, Gao Y B, Guo H Y, et al. 2008. Physiological adaptations of four dominant Caragana species in the desert region of the Inner Mongolia Plateau. Journal of Arid Environments, 72(3): 247-254.

Ma C C, Zhang J H, Guo H Y, et al. 2013. Alterations in canopy size and reproduction of Caragana stenophylla along a climate gradient on the Inner Mongolian Plateau. Flora-Morphology, Distribution, Functional Ecology of Plants, 208(2): 97-103.

Ma C C, Guo H Y, Wu J B, et al. 2014. Acclimation of photosynthetic traits of Caragana species to desert environment in Inner Mongolian Plateau. Arid Land Research and Management, 28(1): 87-101.

May F, Giladi I, Ristow M, et al. 2013. Plant functional traits and community assembly along interacting gradients of productivity and fragmentation. Perspectives in Plant Ecology, Evolution and Systematics, 15(6): 304-318.

Meng M, Ni J, Zhang Z G. 2004. Aridity index and its applications in geo-ecological study. Acta Phytoecologica Sinica, 28(6): 853-861. (in Chinese)

Peco B, Borghi C E, Malo J E, et al. 2011. Effects of bark damage by feral herbivores on columnar cactus Echinopsis (=Trichocereus) terscheckii reproductive output. Journal of Arid Environments, 75(11): 981-985.

Perevolotsky A, Schwartz-Tzachor R, Yonathan R, et al. 2011. Geophytes-herbivore interactions: reproduction and population dynamics of Anemone coronaria L. Plant Ecology, 212(4): 563-571.

Piqueras J. 1999. Herbivory and ramet performance in the clonal herb Trientalis europaea L. Journal of Ecology, 87(3): 450-460.

Romo-Campos L, Flores-Flores J L, Flores J, et al. 2010. Seed germination of Opuntia species from an aridity gradient in Central Mexico. Journal of the Professional Association for Cactus Development, 12(2): 181-198.

Silva H A D, de Moraes A, Carvalho P C D F, et al. 2012. Maize and soybeans production in integrated system under no-tillage with different pasture combinations and animal categories. Revista Ciência Agronômica, 43(4): 757-765.

Volis S, Mendlinger S, Ward D. 2002. Differentiation in populations of Hordeum spontaneum along a gradient of environmental productivity and predictability: life history and local adaptation. Biological Journal of the Linnean Society, 77(4): 479-490.

Volis S, Mendlinger S, Ward D. 2004. Demography and role of the seed bank in Mediterranean and desert populations of wild barley. Basic and Applied Ecology, 5(1): 53-64.

Volis S. 2007. Correlated patterns of variation in phenology and seed production in populations of two annual grasses along an aridity gradient. Evolutionary Ecology, 21(3): 381-393.

Wan H W, Bai Y F, Schönbach P, et al. 2011. Effects of grazing management system on plant community structure and functioning in a semiarid steppe: scaling from species to community. Plant and Soil, 340(1-2): 215-226.

Wang R Z, Gao Q, Chen Q S. 2003. Effects of climatic change on biomass and biomass allocation in Leymus chinensis (Poaceae) along the North-east China Transect (NECT). Journal of Arid Environments, 54(4): 653-665.

Wang R Z, Gao Q. 2003. Climate-driven changes in shoot density and shoot biomass in Leymus chinensis (Poaceae) on the North-east China Transect (NECT). Global Ecology and Biogeography, 12(3): 249-259. 
Wang R Z, Gao Q. 2004. Morphological responses of Leymus chinensis (Poaceae) to the large-scale climatic gradient along the North-east China Transect (NECT). Diversity and Distributions, 10(1): 65-73.

Wang Y T, Deng B, Wang K, et al. 2011. Responses of plant morphology and seed quality to long-term overgrazing in Leymus chinensis. African Journal of Biotechnology, 10(80): 18403-18408.

Xie L N, Ma C C, Guo H Y, et al. 2014. Distribution pattern of Caragana species under the influence of climate gradient in the Inner Mongolia region, China. Journal of Arid Land, 6(3): 311-323.

Xie L N, Guo H Y, Gabler C A, et al. 2015. Changes in spatial patterns of Caragana stenophylla along a climatic drought gradient on the Inner Mongolian Plateau. PLoS ONE, 10(3): e0121234, doi:10.1371/journal.pone.0121234.

Xiong X G, Han X G, Chen Q S, et al. 2003. Increased abundance of woody plants in grasslands and savannas. Acta Ecologica Sinica, 23(11): 2436-2443. (in Chinese)

Yang M H, Guo Z D, Wang C G. 1987. Remote sensing explains about Inner Mongolia Municipality climate types. In: Chen K, Li B. Application Study on Remote Sensing in Inner Mongolia Pasture Resource. Hohhot: Inner Mongolia University Press, 46-58. (in Chinese)

Zhang J H, Ma C C, Liu Z H, et al. 2011. Expansion strategies of Caragana stenophylla in the arid desert region. Acta Ecology Sinica, 31(8): 2132-2138. (in Chinese)

Zhang M L, Huang Y M, Kang Y, et al. 2002. Floristics and vegetation of the genus Caragana in Ordos Plateau. Bulletin of Botanical Research, 22(4): 497-502. (in Chinese)

Zhou H Y, Li X R, Fan H W, et al. 2005. Physiological characteristics of several Caragana shrub species under extreme conditions. Journal of Desert Research, 25(2): 182-190. (in Chinese) 